\title{
Políticas de visibilidade como fatos de afecção: Que ética para as visualidades? ${ }^{1}$
}

\section{RESUMO}

O artigo relaciona o consumo das imagens às teorias da afecção de Spinoza. Assumindo entonação ensaística, problematiza a dimensão política e pergunta se uma Ética é possível para as visualidades. Como somos afetados e como, nós mesmos, afetamos as imagens? Qual a natureza das paixões iconoclastas e iconófilas e em que medida dialogam com embates epistêmicos fundadores do campo da comunicação? Imagens sensacionais, representações da violência aumentam ou diminuem nossa potência de agir? Por que motivos alimentamos, no consumo das visualidades, paixões infelizes?

\section{PALAVRAS-CHAVE}

Imagem

Consumo

Afecção

\section{ABSTRACT}

The article aims to analyze the relationship between image's consumption and Spinoza's theoretical framework, leading to the affections. Adopting an essayistic intonation, put in question the political dimension of Ethics, and also argues if an ethics is possible to analyses visibility. How we are affected by images, and how does we affect them? What is the nature of iconoclasts and idolaters passions and how they dialogue with the epistemic questions that constitute the communication area? Sensationalist's images, representations of violence add or decrease our potency of action? Why we use to adopt, in the consumption of images, unhappy passions?

\section{KEYWORDS}

Image

Consumption

Affections

\section{Rose de Melo Rocha}

Professora do Programa de Pós-Graduação em Comunicação da ESPM/SP/BR. 


\section{Recentemente, motivada pelas reflexóes} de um de meus orientandos ${ }^{2}$, que comigo se dedica a explorar os meandros do consumo (e da consumação) pertinente ao campo imagético, comecei a revisitar alguns de meus antigos escritos, particularmente aqueles nos quais buscava problematizar a contemporânea esfera do consumo das imagens ${ }^{3}$ e, de modo mais específico, a determinância da simbiose mídia/sociedade em processos de estetização da violência ${ }^{4}$. Em um destes momentos, que aqui retomo em assumida entonação ensaística, ocorreu-me propor, seguindo a inspiração do filósofo holandês Benedictus (ou Baruch) de Spinoza (2008), que a discussão sobre políticas de visibilidade poderia ser consubstanciada desde a concepção spinoziana de "afecção". Recorro assim a um dos mais notáveis postulados do pensador para, a partir dele, construir minha argumentação. Discorrendo sobre a origem e a natureza dos afetos, Spinoza propõe que "[o] corpo humano pode ser afetado de muitas maneiras, pelas quais sua potência de agir é aumentada ou diminuída, enquanto outras tantas não tornam sua potência de agir nem maior nem menor" (2008, p. 163).

\section{Ética é justamente associada àquilo que aumenta nossa potência de agir.}

Este pilar fundante das teorias da afecção permite-nos, segundo defendo, entender a dimensão em essência política do que nos é dado a ver, via a profusão de imagens visuais, e, o que particularmente interessa ressaltar, levanos a questionar aquelas que, ao nos afetarem, efetivamente aumentam ou diminuem nossa competência corpórea-cognitiva de ação. Ou seja, é também nesta direção que lanço a pergunta, que intitula este artigo, sobre uma Ética possível para o campo das visualidades posto que, para o mesmo Spinoza (2008), Ética é justamente associada àquilo que aumenta nossa potência de agir.

\section{Como somos afetados e como afetamos imagens?}

Não seria demais lembrar aos leitores que por longos anos de minha vida acadêmica fui uma estudiosa das imagens da violência e dos aterradores processos de sua estetização cotidiana. Também me parece necessário pontuar que, posteriormente, já inserida em um Programa de
Pós-Graduação voltado ao debate intelectual sobre Comunicação e Práticas de Consumo, busquei construir ferramentas analíticas e metodológicas que fossem capazes de tratar as dinâmicas de produção e consumo de visualidades. Coloco estes dados teórico-biográficos em evidência por um motivo bastante simples. Creio que há muito mais em comum entre as, nem sempre virtuosas, imagens da violência e os processos de consumação desencadeados pelo consumo de imagens do que, a princípio, eu mesma poderia supor.

Vejamos: a forte dose "sensológica" 5 que se pode identificar no processo de produção, circulação e consumo de boa parte das imagens midiatizadas da violência, do espetacular e do grotesco, por exemplo, possui, de fato, algo de adição, uma adição que, por razões históricas e dimensões antropológicas, será socialmente reiterada. Valendo-me da precisa análise do psicanalista brasileiro Jurandir Freire Costa, temos que, no caso das imagens da violência de natureza sensacionalista, o que se opera é verdadeiramente uma compulsão, uma paixão infeliz, se quisermos novamente dialogar com Spinoza (2008). O olhar, violentado pela visão de barbáries, insiste patologicamente no retorno às representações sensacionais do horror. Seguindo à terminologia de Freire Costa (1984), adotada em seus estudos sobre violência e narcisismo. Existe nesta experiência algo do plano da neurose traumática, patologia marcada, em uma de suas fases, por "um período de evocação repetitiva do evento traumático". Nesta síndrome, o que surpreende "é a repetição do acontecimento desagradável, defesa oposta ao princípio do prazer" (Freire Costa, 1984, p.171). E aqui podemos formular a seguinte afirmação: esta sensologia estetizante é inegavelmente paradoxal, discursiva e pendular, oscilando entre o pânico anestésico e o gozo catártico. Ela, por exemplo, alimenta o ciclo da violência, ao invés de rompêlo.

Régis Debray (1993), teórico da midialogia, defende que na origem de nossa paixão pelas imagens e atualizando-se ao longo dos séculos, encontramos um fato de crença, mais do que um imperativo da razão. Nossos sistemas de crença visual seriam fartamente ambíguos, circunstanciais e ambivalentes, mas, ainda assim, engendrariam, com perenidade lapidar, sistemas de poder que, curiosamente, pretendem-se da mais radical objetividade. A esta altura de nossa 
argumentação parecerá evidente, o que de modo algum nos desagrada, perceber que retomamos, neste ensaio acadêmico, os clássicos e fervorosos debates entre iconoclastas e iconófilos, que mereceram, em terras brasileiras, os olhares atentos de pensadores como Norval Baitello, Arlindo Machado e Alberto Klein, em inúmeras de suas obras. É realmente das guerras entre razão e sensibilidade que falamos aqui. Assim como, ao debater a vinculação que estabelecemos com imagens dotadas de visualidade, o fazemos para perguntar sobre os liames possíveis entre olhar e produção do conhecimento. Mais do que de uma erudição obscurantista acredito ser auspicioso apreender do estudo das imagens uma nova possibilidade de ver, perceber e narrar o mundo em que vivemos. Este mundo, povoado de corpos. E povoado de imagens, com sua fiel família de materialidades.

\section{Nossos sistemas de crença visual seriam} fartamente ambíguos, circunstanciais e ambivalentes, mas, ainda assim, engendrariam, com perenidade lapidar, sistemas de poder que, curiosamente, pretendem-se da mais radical objetividade.

Se nos detivermos nas investigações desenvolvidas por Jean-Marc Vernier (1988), em suas originais análises da televisão (lugar midiático que opera no cruzamento entre, por exemplo, o real, o ficcional e o tecnológico), torna-se possível uma definição mais próxima da dimensão relacional estabelecida com as visualidades. A proposição do autor refere-se especificamente à elaboração tácita de contratos de visibilidade, "uma sorte de convenção que se estabelece entre o medium TV e o público sobre a natureza do que é dado a ver" (Vernier, 1988, p. 10). Vernier defende ser adequado classificar a imagem televisual a partir de três ordens ${ }^{6}$, cada qual "implicando em certa forma de crença, de adesão, um julgamento daquilo que se mostra, visando um telespectador ideal e prevendo um modo específico de relação deste com as imagens" (Vernier, 1988, p. 10; tradução nossa).

Alain Mons (1994) vai além, perguntandose não apenas sobre os contratos que se firmam, mas problematizando a lógica macrossocial que os ordena. Pesquisador da conformação contemporânea da economia ficcional identifica, em sua lógica, três figuras centrais: imagem, território, comunicação. Mons (1994) procura caracterizar o que chama "o processo metafórico e suas variantes", defendendo que ele nos introduz em uma economia ficcional que se superpõe a uma economia material. Segundo analisa, as duas disposições "formam um entrelaçamento perfeito na complexidade dos intercâmbios" (Mons, 1994, p. 10; tradução nossa). Assim, ter-se-ia que,

(a)s metáforas visíveis dos "campos" nos projetam irresistivelmente para uma poética do social, através dos efeitos de colagem, de superposição das representações, de invisibilidade, de virtualidade, de estalido do sentido. Esta "poética", amplificada em grau máximo e às vezes esterilizada pelas técnicas mediáticas, tem efeitos reais [...]. (A) característica de nossa época é que o sistema das representações, o modo simbólico, se convertem em flutuantes, aleatórios, metafóricos... Trata-se, então, de que descrevamos uma tendência da simbolização, de que proponhamos uma espécie de fenomenologia de um processo de expressividade social no qual ficção e realidade se confundem inextricavelmente, no qual sistemas hiperracionais e acontecimentos irracionais se interpenetram estranhamente (Mons, 1994, p. 10-11; tradução nossa).

Temas como os da representação, da simulação e da referencialidade são tão fundamentais às Ciências da Comunicação quanto o são ao debate antropológico. Todavia, no plano em que particularmente atuamos, este embate epistêmico é determinante. Tal dilema, constitutivo de nossa área de conhecimento, foi problematizado por Lucien Sfez (1994) em seu hermético e não menos inspirador livro Crítica da Comunicação. Sfez (1994) observa que uma crítica à comunicação demanda a distinção primordial entre o que ele qualifica como sendo, respectivamente, o núcleo epistêmico e a forma simbólica da comunicação. Interpretar, neste caso, implica em diferenciar o universo representado do universo da representação, enfrentando o fato de conceitos comuns às ciências da comunicação constantemente migrarem para a vida cotidiana, constituindo-se, em suas palavras, como realidades do mundo social e político. O equívoco a ser desmontado é justamente o da confusão, o fato de tomarmos a realidade representada como realidade diretamente expressa.

Para desfazer o engano, e enfrentando o que ele denomina a força centrípeta da espiral 
comunicativa, o autor apresenta-nos uma nova perspectiva teórica para a compreensão do processo de comunicação, por ele identificado como sendo cada vez mais repetitivo e autoreferente. Lucien Sfez (1994) associa a esta forma do objeto do campo da comunicação - a visão de mundo da confusão - a metáfora do Frankenstein, da criatura que se volta contra o criador, tornandose, para mais uma vez lembrar Spinoza (1994), uma paixão infeliz, que o atemoriza, o aterra, o apavora, submetendo-o. Ou, talvez fosse ainda mais adequado dizer, que o deixa estupefato:

O pavor [...] pode ser mais precisamente definido como o medo que mantém o homem tão estupefato ou hesitante que ele não pode evitá-lo. Digo estupefato, à medida que compreendemos que seu desejo de evitar o mal é refreado pela admiração (Spinoza, 2008, p.255).

Para o crítico da comunicação, o que se passa é uma inversão na qual a tecnologia (tecnologias da comunicação e do espírito) está na base do agir, regendo a visão de mundo. Neste contexto, o homem não poderia existir fora do espelho que ela the estende. Perda da realidade, do sentido, da identidade, com o excesso de informação levando ao fim da comunicação e à morte do sujeito.

Este tensionamento que mobiliza Lucien Sfez (1994) merece, neste ponto do artigo, a acolhida de outro ponto de vista, que, não sendo propriamente a refutação do anteriormente enunciado, irá ampliar-lhe a complexidade. Afinal, e aqui recorrendo às leituras do antropólogo da cultura Edgar Morin (2000), temos que nosso modo de habitar e de fazer mundo responde à entrada em moradas simbólicas que utilizamos para negociar com as incertezas: a casa da linguagem, as produções imagéticas, o universo imaginário, os sonhos, os ritos, os devaneios. Só podemos ser racionais, insiste Morin (2000), porque somos também capazes de descomedimento, porque somos, define o autor, da espécie sapiens-demens.

Nestes termos, a novidade do sapiens é justamente sua capacidade, erigida ao longo de séculos, de decalcar seu cotidiano com todo um grandioso aparato cognitivo que é imaginário e imageante. Vivemos, assim, sempre, em planos de dupla vinculação, em cenários existenciais ambivalentes, posto que são irremediavelmente objetivos e subjetivos. Em tal acepção, a originalidade de nossa espécie não está exatamente em nossa incrível propensão à invenção de técnicas e, posteriormente, de tecno-lógicas. Antes, pondera Morin (2000), a novidade estava colocada em nossas sepulturas e nas pinturas mais originais, residindo, enfim, na capacidade de estruturar complexos imaginários de negociação da finitude, levando-nos a um plano de trans-mortalidade. Não por acaso, as imagens, signos de ausência e de presença, eram, nos primórdios da civilização, consideradas mágicas, temíveis, poderosas. Poucos eram os que podiam ser transformados em "representação", considerada lugar de distinção social ímpar. A história da iconografia religiosa apenas atesta a dimensão política essencial que está imbricada neste processo.

Tais supostos não seriam estranhos a Spinoza (2008). Segundo propõe, o homem é, na mais clamorosa refutação das teorias cartesianas, unidade de corpo e de alma. E este homem, portanto, pode ser afetado com igual intensidade pelo encontro com um animal, um alimento ou com as representações daquilo que deseja, ou do que lhe causa alegria ou ainda do que lhe entristece. Debruçando-se sobre as relações entre as condições da morte e o pensamento do filósofo, Jean-Louis Cianni (2009) escreve: "pensamos ser senhores das circunstâncias, quando na verdade elas zombam de nós; acreditamos ser uma realidade sólida e concreta quando vemos apenas um reflexo ou efeito ótico" (Cianni, 2009, p. 44). Não seria demais afirmar, portanto - e neste caso não estou senão tomada por inspirações de Spinoza (2008) - que podemos desejar ou repugnar com intensidade as representações. Podemos ir além: somos, em nosso indissociável vínculo corpo/mente, capazes de desejar com fervor imagens de coisas e obviamente imagens de nós mesmos. O mito de Narciso apenas confirmaria um dos planos das paixões autoencantatórias e, por vezes, os sedutores desvios do "auto-engano".

Mencionamos anteriormente as imagens da violência. E o que dizer daquelas que sendo espetaculares não poderiam sequer ser facilmente taxadas de perversas? Novamente Spinoza (2008) nos auxilia na compreensão e, ampliando as proposições debordianas, enseja-nos a explorar o lado menos nobre de nossos afetos. Assim, a espetacular profusão das imagens de corpos "famosos", admiráveis ou célebres, a torpe olimpíada de disputas e desqualificações que por tantas vezes ocupa a cena midiática contemporânea não seria de fato estranha ao nosso universo de 
afecções. Afinal, se seguirmos Spinoza (2008) em suas postulações, encontramos que os homens, seus corpos e mentes, padecem de afetos de ódio, ciúme e soberba. Padecem de excessos, que podem, de fato, incapacitá-los de agir: tornam-se presas de suas paixões, "pato-lógicos". Tornamse presas de um descomedimento desejante, que, paralisando-os, fará com que permaneçam, por soberba ou terror, por exemplo, reféns da ordem paralisante de algumas de suas paixões.

\section{Ética, estética, visualidades}

O antropólogo Massimo Canevacci (2008), ao discutir os entrelaçamentos entre corpos humanos, corpos objetais e corpos dotados de visualidade, recorre ao conceito de fetichismo e a uma teoria/ método assumidamente "estupefatos". Contando com estes recursos advoga uma nova abordagem dos laços estabelecidos entre objetos, corpos e imagens, construindo uma linha argumentativa que, segundo analiso, pode ser interpretada como sendo de uma erótica, das visualidades. É novamente o desejo que se instala aí, nesta crítica da reificação visual que recusa análises pregressas, apreendendo o fetichismo para além dos planos da alienação (Marx) e da perversão (Freud).

Para Canevacci (2008), há uma lógica e um discurso publicitário sempre ali, costurando simbólica e literalmente as existências, como se, de fato, a idéia de uma automação tivesse se deslocado dos corpos de metal, de madeira, de eletricidade e ondas magnéticas para o bios humano. E isto talvez possa ser atribuído à centralidade das visualidades na cena social e afetual da atualidade, imagens que, longe de serem ideologizadas, expressam paradigmaticamente a lógica sexualmente fantasmática que ordena o socius, mas, fundamentalmente, que rege, como sub-reptícia palavra de ordem, a dominância de mecanismos imaginários na regulação e desregulação social.

Se uma esperança existe, sugere Canevacci (2008), ela reside na sedução, nas iniciativas intersticiais de cruzar e juntar improbabilidades estéticas, anatômicas, eróticas, teóricas. Mutações culturais sincréticas ganham visibilidade, consolidando, no argumento do autor, algumas proposições. Uma delas soa emblemática. Segundo o antropólogo, a experiência com os fetiches e a fetichização, lança-nos um desafio a um só tempo cognitivo e perceptual, impelindo o olho "a refinar-se em eróptica" (Canevacci, 2008, p. 263). A crítica à reificação visual, portanto, exige, nestes termos, não se temer o mergulho incessante na arriscada e ambivalente sedução das visualidades e dos próprios fetiches. E isto só se pode fazer em fluxo, na disposição mesma para as metamorfoses.

W. J. T. Mitchel (1987), teórico da iconologia, dedica-se a discussão similar, ao perguntar-se o que, afinal, são e desejam as imagens. Para o autor americano, imagem "[...] não é simplesmente um tipo particular de signo, mas um princípio fundamental do que Michel Foucault chamaria 'a ordem das coisas'" (Mitchell, 1987, p. 11; tradução de Rocha e Portugal). Neste sentido, a imagem é um acontecimento híbrido, exatamente porque mistura sujeito e objeto. É através dela, na verdade, que estes dois podem existir como "representação", no sentido schopenhaueriano (Rocha; Portugal, 2008). O "mundo como representação", para Schopenhauer (2001), surge na medida em que, a partir de estímulos (efeito), intuímos - talvez pudéssemos dizer "imaginamos" - objetos no tempo e no espaço (causas). Assim, "toda noção de um objeto propriamente dito, isto é, de uma representação perceptível no espaço, só existe por e para o entendimento: longe de precedê-lo, deriva dele" (Schopenhauer, 2001, p.20).

Edgar Morin, em seus precursores estudos sobre a condição humana (2000) e o encanto das imagens (1997), defende que a experiência da duplicidade nos constitui: somos natureza e cultura, sapiens e demens, finitos e eternizáveis. A imagem, na leitura moriniana, deverá inexoravelmente ser percebida desde algumas destas duplas fundações. Em primeiro lugar, ela existe na hibridação de sentimentos que mesclam um estar a um não-estar: a imagem é ausência de uma presença e presença de uma ausência. Paralelamente, imagens são duplos dos próprios homens, numa gênese de materialização que é, em si, vinculada a experiências de negociação com planos de imaterialidade e invisibilidade. As imagens dos sonhos, as imagens das sombras, as imagens das visagens e as imagens das visualidades operariam, desta forma, em uma linha fronteiriça de irrealidade e de realização. E seria exatamente esta zona de hibridação entre o visível e o invisível o berço e a efetiva matriz da vida simbólica das imagens, estas que, muitas vezes, são decalcadas em objetos, corpos, suportes e midialidades (Rocha; Portugal, 2008).

Jean Baudrillard (1992), com sua verve provocadora, defendeu, em algumas de suas mais 
polêmicas obras, a existência de um gênio maligno dos e nos objetos. Afinal, o mal estar da visualidade revela que algo nos olha sem que disto suspeitássemos. Há algo ali que se disfarça e se revela, sem que nunca saibamos ao certo o jogo que, em determinado momento, se está a jogar. São elas, as imagens, com sua alma irônica, que estão a nos olhar. São elas, e não o inverso, que desejam o nosso olhar, em uma cada vez mais forte adição. Nós somos seu vício e elas o nosso destino fatal.

A guerra às imagens, que por séculos inflamou epistemólogos e teólogos, parece fragilizada ante o domínio inegável que elas assumem em um mundo em franco estado de abstratificação, este universo do pós-espetáculo sobre o qual nos debruçamos e que, incessantemente, sedutoramente, nos faz capitular, bela palavra para descrever o encanto caprichoso que nos oferecem algumas imagens. $\mathrm{O}$ mais difícil, neste aspecto, tem sido explicar como, cultuando as abstrações, nos coloquemos fortemente engajados no terreno das literalidades.

Nas sociedades midiáticas, definitivamente operando graças a um sistema produtivo que lucra com o comércio de representações, os humanos, ao mesmo tempo em que cultuam seus deuses de símbolos e luminosidades, defendem, com o descrédito digno de ascetas, uma demanda por objetividades, por explicações as mais "concretas" possíveis, que supostamente, não se sabe exatamente por qual motivo, conduziriam a uma solidez de explicações, a uma veracidade etereamente clara, imune que estaria a toda e qualquer falibilidade. A gravidade de tal processo é insuspeita. Seres que a um só tempo crêem em imagens e crêem em uma essência das coisas, em uma literalidade do mundo, que, em última instância, possuiria uma verdade inegável, vivem no cerne de um fulcro humanístico radical. Tais sociedades poder-se-ia argumentar, restringiram o mundo do espírito a um plano patologicamente autônomo, tratando-o, a rigor, como uma segunda e irrefutável natureza.

Jean-François Lyotard (1986), quando escreveu sobre a condição pós-moderna, estava particularmente interessado em denunciar os limites que identificava na filosofia em relação à sua crescente impossibilidade de construir interpretações de cunho universal e aproximações analíticas consistentes do instável mundo contemporâneo, um mundo que mudara muito intensa e rapidamente inclusive em seus fundamentos produtivos. O nú- cleo da problematização lyotardiana articulava-se à derrocada filosófica em seu caráter de ciência das ciências, embora o mesmo autor tenha incansavelmente buscado, até seus derradeiros escritos, identificar os lugares ainda possíveis para seu exercício e suas legitimações possíveis.

A percepção do desmoronamento dos castelos de cristal acadêmicos seria associada à emergência avassaladora das novas tecnologias, aquelas que para o filósofo Lyotard (1986) incidiriam radicalmente na lógica de produção do saber e nas dinâmicas de divulgação e disseminação do conhecimento. Segundo analisava, a crise dos relatos abalara os jogos de legitimação do saber acadêmico, o que, para ele, estava diretamente associado à entrada das sociedades na etapa pós-industrial e na submissão do pensamento à performativa lógica da racionalidade técnica.

As narrativas da pós-modernidade colocarse-iam nestes termos em um fio da navalha e, o que não é desimportante, levariam consigo a técnica, a arte, a sensibilidade e a racionalidade o projeto da razão iluminista na linha de frente. Afinal, e por isto elas têm sido tão fortemente questionadas, estas narrativas fragmentadas ou localistas, forjadas em um tempo de incerteza ontológica e crise das metanarrativas, questionam a existência de uma verdade única e essencialista, e expõem ou colocam em relevo o que consideram a inevitável constatação de um enfraquecimento da interpretação, incidindo também na crescente incapacidade de o homem se auto-representar.

Aqui, no cerne do mal-estar, vários pensadores assumiram como missão intelectual e ideológica denunciar alguns efeitos indesejáveis da modernidade, que teria nos brindado com o peso do "fazer sentido" a todo custo e, tendo-o feito em tal descomedida proporção, terminou paradoxalmente por nos mergulhar em um mar de sem sentido. Não por acaso, ganham força neste contexto argumentações incisivas sobre a crise do sujeito, sobre o fim da história linear e a pulverização da ação política.

Zygmunt Bauman (1998), por exemplo, argumenta que, em sua versão hegemônica, os grandes vetores da aventura moderna - materializados pela tríade beleza (harmonia), pureza (limpeza) e ordem - significaram o pagamento $a$ posteriori de uma conta profundamente incômoda. O excesso de ordem, polemiza o autor, nos conduziu a uma escassez de liberdade. Assistindo nas líquidas sociedades contemporâneas à emergência de processos de desregulamentação, homens 
e mulheres encarariam com vasta permissividade o preço que devem pagar para a entrada no reino encantatório da liberdade individual. Neste, a liberdade - individual - de busca do prazer a todo custo, toleraria uma segurança - também individual - pequena demais.

Com estas observações, chegamos à "pós-modernização", diretamente associada ao capitalismo em sua etapa pós-industrial, tecnológica, de serviços e tendendo à imaterialização. Este capitalismo de última fase, pós-fordista, teria nas imagens e nas visualidades sua grande mercadoria e nos meios de comunicação seu grande ordenador social. Na pós-modernização, o sistema produtivo é essencialmente midiático e a base financeira estritamente mundializada e tecnologizada.

Em um ponto de vista especificamente comunicacional, podemos destacar algumas tematizações que mais fortemente caracterizam a incorporação de discursos pós-modernos a esta área do conhecimento. Sem dúvida, há uma recorrência de estudos que se apropriam das narrativas pós-modernas, e de seus críticos, para analisarem a cidade, o corpo, as tecnologias e as imagens. Em um sentido mais amplo, também se pode perceber o recurso a tais teorias para analisar o status corrente da comunicação, tanto em termos epistêmicos estritos, quanto em suas dinâmicas produtivas e simbólicas, com inúmeras atualizações de conceitos como sociedade do espetáculo, cultura do consumo e cultura midiática.

Se estiver correto Fredric Jameson (2002), ao apontar que a lógica cultural é, hoje, o capitalismo tardio, podemos destacar, igualmente, que a lógica visual é paradigmática das políticas de significação contemporâneas. O "fazer ver" associa-se assim ao "fazer sentido", ou, antes, ao "fazer sentir" inerente aos processos de estetização da vida cotidiana, tão próprios a esta que aqui denominamos uma cena pós-moderna.

A tensa união entre Ética e Estética ainda é nosso remédio para enfrentar o cinismo. Agir, com nossos corpos desejantes, ainda é nosso destino menos fatal. Finalizo minhas provocações analíticas unindo, em um casamento um tanto inesperado, dois autores. De um lado, Jesus Martín-Barbero (2004), o cartógrafo mestiço. De outro, tenho Guy Debord (1967), o pensador do espetáculo.

Da compreensão dos textos debordianos é fundamental considerar que à crítica cultural por ele articulada associa-se um claro princípio de enfrentamento político detectado desde os interstícios da prática cotidiana. Assim, suas teorias - diagnósticas e indicativas de "profilaxias" possíveis - serão pensadas como imperativamente imersas neste dia-a-dia. Em sentido complementar, a contestação como modo de vida percorre com intensidade sua práxis. E isto não se dá por acaso: a Debord (1967) interessava denunciar a debilidade espiritual das esferas públicas e privada por ele atribuída às forças econômicas que dominaram a Europa após a modernização decorrente do final da Segunda Grande Guerra. Para Guy Debord, a vida em tempos de espetáculo atomiza-se e se banaliza, com o encarceramento e isolamento dos indivíduos, presas que estariam de uma rede de compensações cuidadosamente agenciada.

\section{Uma Ética das visualidades é uma cartografia especular, assim como uma imagéticaé um exercício de reciclagem do visível. Uma imagética não se filia de modo irrestrito a tradiçóes iconoclastas nem a iconofilias românticas}

De Martín-Barbero (2004), empresto a embocadura cartográfica com seus "des-centramentos do olhar" e rupturas epistemológicas: "a necessidade de mudar o lugar desde onde se formulam as perguntas" e o reconhecimento da comunicação como "um enclave estratégico do pensar" (Martín-Barbero, 2004, p. 26-34). Com ele proponho: uma Ética das visualidades é uma cartografia especular, assim como uma imagética é um exercício de reciclagem do visível. Uma imagética não se filia de modo irrestrito a tradições iconoclastas nem a iconofilias românticas.

Este exercício do olhar, e do como olhar, responde a uma proposição: só nos resta, enfim, indagar. Melhor talvez possamos dizer: decupar visualidades, desmembrar fragmentos não para lhes devolver, através do discurso científico, uma nova organicidade. Nesta experiência de interpretação bricoladora, o olhar detém-se na pele das superfícies. (Rocha, 2009). Nela, a potência de agir significa a visada fundamental para um ser no mundo que é, em última instância, um sujeito de coletividade. Nela, a ação, contaminada pelos afetos felizes, é cartografada na estética cotidiana. Naquela em que, sendo tantos, podemos nos reconhecer sujeitos. Em relação. Em comunhão. A 
Ética de que falo é, em termos cabais, uma poética da convivialidade. Tensa e conflituosa como toda união possível. Imageante e imaginária como toda existência. É de uma utopia talvez que fale meu discurso sobre o consumo (ético) de imagens. É assim, neste muito além dos cortes moralizantes, que, talvez, possamos civilizar a dita civilização das imagens. Conhecendo o que elas desejam de nós. E nem sempre agindo movidos pela paixão que nelas desejamos desejar.

\section{REFERÊNCIAS}

BAUDRILLARD, Jean. A transparência do Mal. Ensaio sobre os fenômenos extremos. Campinas: Papirus, 1992.

BAUMAN, Zygmunt. O Mal-estar da Pós-modernidade. Rio de Janeiro: Jorge Zahar Ed., 1998.

CANEVACCI, Massimo. Fetichismos Visuais. Corpos Erópticos e Metrópole Comunicacional. São Paulo: Ateliê Editorial, 2008.

DEBORD, Guy. A sociedade do espetáculo. Rio de Janeiro: Contraponto, 1997.

DEBRAY, Régis. Vida e morte da imagem: uma história do olhar no ocidente. Petrópolis: Vozes, 1993.

FOUCAULT, Michel. As palavras e as coisas. São Paulo: Martins Fontes, 2007.

FREIRE COSTA, Jurandir. Violência e psicanálise. Rio de Janeiro: Graal, 1986.

HARVEY, David. Condição Pós-moderna. São Paulo: Loyola, 1992.

JAMESON, Fredric. Pós-modernismo. Lógica Cultural do Capitalismo Tardio. São Paulo: Ática, 2002.

KAPLAN, E. Ann (org.). Pós-modernismo. Teorias, Práticas. Rio de Janeiro: Jorge Zahar Ed., 1993.

LYOTARD, Jean-François. O Pós-moderno. Rio de Janeiro: José Olympio, 1986.

MARTÍN-BARBERO, Jesus. Ofício de cartógrafo. Travessias latino-americanas da comunicação na cultura. São Paulo: Loyola, 2004.

MITCHEL, Willian J.T. Iconology: image, text, ideology. Chicago: The University of Chicago Press, 1987.

What do pictures want? The lives and loves of images. Chicago: University Of Chicago Press, 2005.

MONS, Alain. La metáfora social. Buenos Aires: Nueva Visón, 1994.

MORIN, Edgar. O cinema ou o homem imaginário. Lisboa: Relógio D’Água, 1997.

. O paradigma perdido. A natureza humana. Lisboa: Europa-América, 2000.
PERNIOLA, Mario. Do sentir. Lisboa: Presença, 1993.

ROCHA, Rose de Melo. É a partir de imagens que falamos do consumo. In: BACCEGA, Maria Aparecida (Org.). São Paulo: ESPM, 2009.

Estética da violência. Por uma arqueologia dos vestígios. 1997. Tese (Doutorado) - ECAUSP, São Paulo, 1997.

ROCHA, Rose de Melo; PORTUGAL, Daniel. Trata-se de uma imágica? In: ARAÚJO, Denise; BARBOSA, Marialva. Imagíbrida. Porto Alegre: Editora Plus, 2008. (e-book).

SCHOPENHAUER, A. O mundo como vontade e representação. São Paulo: Contraponto, 2001.

SFEZ, Lucien. Crítica da Comunicação. São Paulo: Loyola, 1994.

SPINOZA, Benedictus. Ética/Spinoza. Belo Horizonte: Autêntica, 2008.

VERNIER, Jean-Marc. Trois ordres de l'image télévisuelle. In: Quaderni, n. 4, primavera de 1988. Paris: CREDAP, Université Paris Dauphine. p. 9-18

VIRILIO, Paul. O Espaço Crítico. Rio de Janeiro: Editora 34, 1993.

\section{NOTAS}

1 Trabalho apresentado ao Grupo de Trabalho "Comunicação e Cultura", do XIX Encontro da Compós, na PUC-Rio, Rio de Janeiro, em junho de 2010.

2 Refiro-me aos estudos de Daniel Portugal, que recentemente concluiu, sob minha orientação, a dissertação de Mestrado "A imagem entre vinculações e interpretações: consumo, mídia e estetização pelas lentes da Comunicação e da Iconologia", articulada à pesquisa "Consumo e cena midiática: culturas juvenis e políticas de visibilidade no Brasil", que desenvolvo junto ao PPGCOM-ESPM, na cidade de São Paulo.

3 Alguns dos mais relevantes apresentados em encontros anteriores da Compós e sintetizados em Rocha (2009).

4 A esse respeito, ver Rocha (1998).

5 Adoto o termo seguindo as proposições de Mario Perniola (1993) que definirá a sensologia como um modo de sentir o mundo paradigmático das sociedades midiáticas. Tudo é perpassado pelo sentir, que adquire uma dimensão anômica, primado de uma sensologia da exaustão e da monotonia. Tratar-se-ia de um sentir desprovido de surpresa, sentir obrigatório. O já-sentido é experiência jogada para fora de nós, através da qual o mundo cheganos já provado (Perniola, 1993, p. 14,16,17).

6 Imagem-profundidade, com um contrato de credibilidade, na presunção de uma objetividade pura; imagemsuperfície, com a qual o contrato é o do espetáculo, baseado na primazia da mise-en-scéne; e imagem-fragmento, com seu contrato energético, pulsante, ligado à pura sensação. 